Eastern Illinois University

The Keep

Faculty Research \& Creative Activity

Business, School of

January 2012

\title{
The Role of National Culture on Relationships Between Customers' Perception of Quality, Values, Satisfaction, and Behavioral Intentions
}

Chao Wen

Eastern Illinois University, cwen@eiu.edu

Hong Qin

University of Texas - Pan American

Victor R. Prybutok

University of North Texas

Charles Blankson

University of North Texas

Follow this and additional works at: http://thekeep.eiu.edu/business_fac

Part of the Business Commons

\section{Recommended Citation}

Wen, Chao; Qin, Hong; Prybutok, Victor R.; and Blankson, Charles, "The Role of National Culture on Relationships Between Customers' Perception of Quality, Values, Satisfaction, and Behavioral Intentions" (2012). Faculty Research \& Creative Activity. 9. http://thekeep.eiu.edu/business_fac/9 


\section{The Role of National Culture on Relationships Between Customers' Perception of Quality, Values, Satisfaction, and Behavioral Intentions}

Chao Wen, Eastern Illinois University

Hong Qin, University of Texas Pan American

Victor R. Prybutok, University of North Texas

Charles Blankson, University of North Texas

The purpose of this paper is to examine the influence of individualistic cultures (such as the American culture) and collectivistic cultures (such as the Chinese culture) on the interrelationship among service quality, food quality, perceived value, customer satisfaction, and behavioral intentions in the fast-food industry. First, the authors provide empirical evidence of the robust relationships among the constructs across diverse cultures. Second, they investigate how moderator variables such as customer age, gender, and national culture affect customer behavioral intentions. Moreover, they examine how national culture, as a moderator, affects the magnitude of the relationships among these constructs. Using survey data collected from the United States and China, results indicate that national culture does have a moderating effect on the relationships and there are differences in the behavioral intentions of American and Chinese customers. More specifically, in the United States, service quality and food quality have a stronger influence on customer satisfaction than in China. Also, the effect of perceived value on customer satisfaction and the effect of customer satisfaction on customers' behavioral intentions are stronger in China than in the United States. Overall, the findings provide rare crosscultural insights and thus serve as building blocks for strategies in the global fast-food domain.

Key words: culture differences, fast-food industry, service quality, structural equation modeling

\section{INTRODUCTION}

Service industries are growing fast in the global marketplace, with many service organizations seeking profits and competitive advantages by focusing on service quality and customer satisfaction. However, as expected, customers in different countries have different perceptions of service quality due to cultural and environmental differences. Therefore, as stated by Laroche et al. $(2004,59)$, "Cultural differences must be taken into account in the study of measurement of service quality and satisfaction." Moreover, studies have focused on the impact of cultural differences on consumer behavior, including decision-making style (Fan and Xiao 1998), the measurement of service quality and satisfaction (Laroche et al. 2004), customer's perception of congestion, and attribution (Ki, Wen, and Doh 2010). 
Among the cross-cultural research and in the context of social behavior, the most important dimension is the difference between individualist cultures in the West (for example, Northern European and North American) and collectivist cultures in the East (for example, East Asian and Mediterranean) (Kim, Wen, and Doh 2010). The United States is deemed as the most individualistic culture in the West (Hofstede 1991), while China is considered as the most collectivistic culture-with the largest population-in the East. Though many studies have investigated the cultural differences between the United States and China, to date, not much research has been documented on customer behaviors in the service industry (Kim, Wen, and Doh 2010). While the current and potential growth of the Chinese fast-food market is attractive to American fast-food franchises, differences in culture between Chinese and American customers are barriers for transplanting successful business strategies into China. To that end, the purpose of this study is to compare the effect of individualistic and collectivistic cultures in the context of the fast-food industry using American and Chinese customers as an illustration. The fast-food industry has been developing rapidly throughout the world. According to a report from Datamonitor (2010), the global fast-food market is predicted to have a value of $\$ 239.7$ billion and a projected volume of 248.7 billion transactions by 2014 .

The United States currently leads the global fastfood market and controls 52.4 percent of the market share, with franchises in more than 100 countries (Datamonitor 2009). China is experiencing remarkable growth in the fast-food industry, one of the greatest growing restaurant sectors in the country, with annual market growth rates in excess of 25 percent between 2008 and 2011(RNCOS EServices Private Limited 2008). The latter has led to more and more franchises crossing national boundaries into China.

While the global development of fast-food restaurants (FFRs) has created opportunities, at the same time, significant challenges exist because of cultural differences. In light of this, fast-food managers need to be conversant with and appreciate the complexity of national cultures before applying their experiences from domestic markets into foreign markets (Brady, Robertson, and Cronin 2001). In addition, because the fast-food industry is viewed as a service industry (Parasuraman, Zeithaml, and Berry 1985), there is increasing attention on the importance of service quality, service value, and customer satisfaction in FFRs in the United States and other countries that exhibit individualist cultures (Kara, Kaynak, and Kucukemiroglu 1995; Brady, Robertson, and Cronin 2001; Gilbert et al. 2004). However, the question that appears to have been overlooked by scholars is what factors are important to successfully doing business in collectivistic cultures? In other words, will some other determinants such as perceived value and food quality be more important than service quality in collectivistic markets? These questions are opportune research tasks.

Qin, Prybutok, and Peak (2009) proposed to examine the differences in how Chinese customers and American customers perceive service quality, food quality, and value 
in the fast-food industry. In their study, they proposed that Chinese customers place higher value on personal attention, reliability, and trust (H5), while American customers are more concerned about recoverability and responsiveness (H6). In terms of antecedents of customer satisfaction, food quality and price are more important to Chinese customers than to U.S. customers (H7); and service quality is more important to U.S. customers (H8). To examine the hypotheses, two samples, one from China and another from the United States, were used. Exploratory factor analysis (EFA), confirmatory factor analysis (CFA), and structural equation modeling (SEM) using LISREL were employed to analyze these two samples separately. However, that study did not test the hypotheses for the influence of culture using a comparative methodology, but rather they compared models developed separately in each country. As a result, that methodology was intended to address how each culture influenced the results on a single homogeneous model but focused on comparing how constructs such as reliability, empathy, trust, recoverability, responsiveness, food quality, and service quality perform differently within Chinese customers and U.S. customers separately. In that work none of the hypotheses related to cultural differences (H5, H6, H7, and H8) were supported, but the results of that data analysis methodology are not intended to suggest that culture does not moderate the relationships within the model. Testing such moderation is the goal of this research, along with the inclusion of the moderator variables of gender and age.

What appears to be missing in Qin, Prybutok, and Peak's study (2009) is that they did not explore the issue of culture as a moderating effect on the relationship between service quality, customer satisfaction, and customer behavioral intentions within the same model. Thus, the authors initiated an investigation of the common factors that affect customer behavioral intentions across the two different countries and how these differences moderate the relationships within a homogeneous model. To that extent, the current study contributes to the literature by providing rare insights into national cultures (that is, the United States and China) and FFR interface with customers' behavioral intentions and then putting forward normative guidelines for the management of FFRs in the global marketplace.

More specifically, the purposes are twofold. First, the authors provide empirical evidence of the robust relationship between food/service quality, perceived value, customer satisfaction, and behavioral intentions across diverse cultures. Second, this paper investigates how moderator variables like customer age, gender, and cultural differences between the United States and China affect customer intentions to return, and in particular how national culture, as a moderator, affects the magnitude of the relationships among these constructs.

The organization of the paper is as follows. Following a review of the literature and the subsequent development of a research framework and hypotheses, the authors describe their research methodology in three steps: 1) a combined sample data collected from China and the United States is used to examine the relationship between the constructs across diverse cultures; 2) the direct effects of the 
moderator variables on customer behavioral intentions are then explored; 3) in order to examine the distinctions in customer behavioral intentions with different culture, the authors separate the data set into two groups-the United States sample and the China sample-and then examine the moderating effect of national culture in the research model. After presenting the results, the authors conclude and then discuss their research findings with theoretical and managerial implications.

\section{THEORETICAL BACKGROUND AND HYPOTHESES}

Antecedents to Customer Behavior Intentions in FFRs

The literature review suggests that the concept of service quality plays a central role in understanding how to maintain core competitiveness and improve business performance. The importance of service quality is substantially addressed in fastfood management literature (for example, Lee and Ulgado 1997; Brady, Robertson, and Cronin 2001; Gilbert et al. 2004; Keillor, Hult, and Kandemir 2004; Qin and Prybutok 2008). Customer perceptions of service quality are important to international organizations because they are susceptible to cultural variations (Mattila 1999; Furrer, Liu, and Sudharshan 2000). Companies are compelled to assess and improve their service quality continuously in an effort to attract customers (Gilbert and Veloutsou 2006). Poor service quality may lead to customer dissatisfaction and reduce customer intentions to dining at the same FFR. Worse, other customers may change their FFR choice because of word-of-mouth communication with unsatisfied customers (Gilbert et al. 2004). Most of these unsatisfied customers never inform the company about their feelings. Research suggests that 90 percent of these "silent critics" take their business to a competitor (Qin and Prybutok 2008). FFRs that provide superior service quality and have a more satisfied customer base also experience higher financial returns, and this applies to both the domestic and international markets (Gilbert et al. 2004; Gilbert and Veloutsou 2006; Malhotra et al. 2005).

There is strong theoretical and empirical support for the relationships among service quality, customer satisfaction, and behavioral intentions in fast-food industries (for example, Brady, Robertson, and Cronin 2001; Qin and Prybutok 2008). However, service quality is not the only determinant of customer satisfaction and purchase intentions. Convenience, low price, food quality, and availability are also reasons why people dine in FFRs. Several recent efforts have extended the researchmodel and investigated food quality and perceived value as additional potential determinants of customer satisfaction and behavioral intentions in FFRs (for example, Johns and Howard 1998; Kivela, Inbakaran, and Reece 1999; Kim and Kim 2004; Kara, Kaynak, and Kucukemiroglu 1995; Qin and Prybutok $2008 ; 2009)$. A review of the literature indicates that existing studies have examined different factors that influence customer perception, attitude, or behavior in fastfood restaurants. Interestingly, the significances of the impact of these factors are 
not consistent. The authors summarized these factors and research findings from these studies in Table 1. Even though different factors are examined in previous studies, all of these factors can be generalized into service-related instruments, food-related instruments, and price-value-related instruments.

\begin{tabular}{|l|l|l|}
\hline \multicolumn{3}{|l|}{ Table 1 A selection of empirical work dealing with fast-food restaurants. } \\
\hline Study & Factors and research findings & Methodology \\
\hline $\begin{array}{l}\text { Lee and Ulgado } \\
\text { (1997) }\end{array}$ & $\begin{array}{l}\text { Significant differences of customers' expectations and perceptions of } \\
\text { FFR service quality, food price, service time, and location between } \\
\text { the United States and South Korea. }\end{array}$ & $\begin{array}{l}\text { Survey data collected from the United } \\
\text { States and South Korea. Analysis with } \\
\text { regression }\end{array}$ \\
\hline $\begin{array}{l}\text { Brady, Robertson, } \\
\text { and Cronin (2001) }\end{array}$ & $\begin{array}{l}\text { Service quality affects behavior intentions through satisfaction in both } \\
\text { North America and latin America. Service value affects behavior } \\
\text { intentions in North America but not in Latin America, which means } \\
\text { American consumers are more value conscious than Latin American. }\end{array}$ & $\begin{array}{l}\text { Survey data collected from North } \\
\text { America and latin America. Analysis } \\
\text { with SEM in LSREL }\end{array}$ \\
\hline $\begin{array}{l}\text { Law, Hui, and } \\
\text { Zhao (2004) }\end{array}$ & $\begin{array}{l}\text { Waiting time, staff attitude, environment, seat availability, and food } \\
\text { quality influence return frequency; waiting time, staff attitude, food } \\
\text { quality and food variety affect customer satisfaction. }\end{array}$ & $\begin{array}{l}\text { Survey data collected from Hong Kong, } \\
\text { analysis with GLM in STATISTICA }\end{array}$ \\
\hline $\begin{array}{l}\text { Keillor, Hult, and } \\
\text { Kandemir (2004) }\end{array}$ & $\begin{array}{l}\text { Service encounter including physical good quality, service quality, } \\
\text { and servicescape positively influence behavioral intentions. }\end{array}$ & $\begin{array}{l}\text { Survey data collected from eight } \\
\text { countries, analysis using SEM in LISREL }\end{array}$ \\
\hline $\begin{array}{l}\text { Qin and Prybutok } \\
\text { (2008) }\end{array}$ & $\begin{array}{l}\text { Service quality with five dimensions affects behavior intentions directly. } \\
\text { Food quality and price/value are found to be significant factors on } \\
\text { customer satisfaction and behavioral intentions. }\end{array}$ & $\begin{array}{l}\text { Survey data collected from the United } \\
\text { States Analysis with SEM in LSREL }\end{array}$ \\
\hline $\begin{array}{l}\text { Ryu, Hon, and } \\
\text { lang (2010) }\end{array}$ & $\begin{array}{l}\text { Hedonic and utilitarian values significantly affect customer satisfoction } \\
\text { that additionally has strong influence on behavioral intentions. }\end{array}$ & $\begin{array}{l}\text { Survey data collected from United } \\
\text { States. Analysis with SEM in AMOS }\end{array}$ \\
\hline
\end{tabular}

Researchers and FFR managers need to know the most important factors that will influence customers' satisfaction and behavioral intentions in the global marketplace, and whether customers in different nations have different perceptions of service/ food quality, value, and satisfaction. As noted earlier, given that customers in different cultures exhibit unique behavioral characteristics and various expectations (Lee 2007), the concept of service quality can be measured more accurately with a cross-cultural sample dataset. It is important to note that unstable dimensionality of service quality instruments exists in different servicerelated studies. A general scale of service quality is the five-dimension SERVQUAL instrument based on gap theory (Parasuraman, Zeithaml, and Berry 1988), and the fit of this scale has been tested in many industries. The performance-based SERVPERF instrument (Cronin and Taylor 1992) incorporated the original five SERVQUAL dimensions and 22 items. However, the gap scales were replaced with perceptions that measure service quality. In some studies, SERVPERF is considered to be more valid, reliable, and powerful than SERVQUAL (for example, Cronin and Taylor 1992; Jain and Gupta 2004). Nevertheless, SERVPERF is still a generic instrument of service quality rather than an instrument designed to measure service quality in the FFR's context. Qin and Prybutok (2008) examined the five key determinants of service quality (tangibles, reliability, responsiveness, assurance, 
and empathy) in the fast-food industry. In their later research (Qin, Prybutok, and Peak 2009), another potential dimension, recoverability, was incorporated along with SERVPERF and then tested. The authors found that in addition to the five dimensions of SERVPERF, recoverability is also an important dimension for measuring service quality in FFRs.

\section{Figure 1 Research model.}

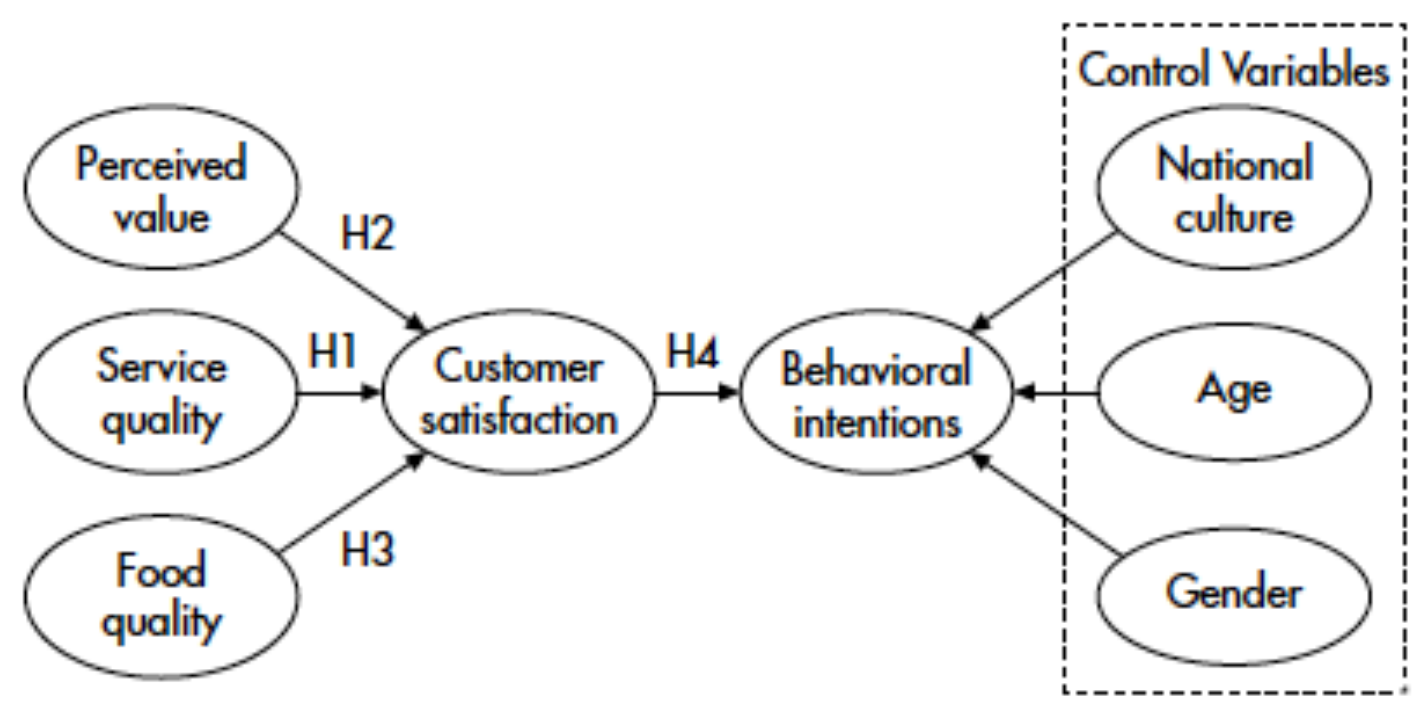

This study adapts the model proposed by Qin and Prybutok (2008) to identify the influences of food quality, service quality, and price value on customer behavioral intentions through customer satisfaction in FFRs. The authors' study puts forward four hypotheses geared toward examining whether this parsimonious model fits diverse national cultures, and hence providing empirical evidence of the robust relationships among the constructs. In addition, they examine moderator variables such as gender, age, and national culture on customer behavioral intentions. As a result, four hypotheses were generated and the research model is shown in Figure 1:

- H1: In the global fast-food market, customer perception of service quality has a direct and positive influence on customer satisfaction.

- H2: In the global fast-food market, perceived value of food has a direct and positive influence on customer satisfaction.

- H3: In the global fast-food market, food quality has a direct and positive influence on customer satisfaction.

- H4: In the global fast-food market, customer satisfaction has a direct and positive influence on customer behavioral intentions.

\section{Moderating Effect of National Culture}

National culture has been defined as "patterns of thinking, feeling, and acting that 
are rooted in common values and societal conventions" (Laroche et al. 2004, 62). Several studies have addressed the effect of cultural differences across countries in the context of food restaurants. Lee and Ulgado (1997) compared the United States and South Korean samples using the regression model and found that food prices and assurance were important for American customers, while reliability, empathy, and lower prices were significant factors in determining overall service value for South Korean customers. Moreover, Brady, Robertson, and Cronin (2001) found that while American fastfood consumers emphasize the importance of service value, Ecuadorian consumers stress satisfaction on their behavioral intentions. Gilbert et al. (2004) found that satisfaction with personal setting and service setting was the common measurement of customer satisfaction across four Englishspeaking countries. Qin, Prybutok, and Peak (2009) proposed hypotheses that Chinese customers place greater emphasis on food quality, reliability, empathy, and trust, while American customers stress service quality, recoverability, and responsiveness. However, none of these proposals were supported by their statistical analysis. The authors believe that the cultural differences between the United States and China will influence customers' behavioral intentions; therefore, this study tests the moderating effect of national cultures between the United States and China on the research framework proposed in the last section.

Individualism versus collectivism is an idea generally considered as the summary of the major cultural difference between the United States and China (Hofstede 1991). Research indicates that people with individualistic cultures discover and express themselves based on internal feelings instead of those of others (Kim, Wen, and Doh 2010). On the other hand, collectivistic cultures such as in China are embedded in the Confucian culture, which has two important social influences: 1) group conformity pressure; and 2) the concept of face (Laroche et al. 2004). It is worthy to note that the major differences between Chinese and American consumers are now well documented in the literature (for example, Friedman, Chi, and Liu 2006; Chan and Wan 2008; Qin, Prybutok, and Peak 2009; Kim, Wen, and Doh 2010).

In the United States, customers have a diverse array of choices of FFRs with equal perceived value. Therefore, the perceived value does not appear to be important to the average American customer. It is believed that perceived value does not explain much of the variation of customer intentions to return compared with other factors (Qin, Prybutok, and Peak 2009). Conversely, service quality and food quality exhibit more significant variances of customer satisfaction and behavioral intentions for American customers. Chinese customers, on the other hand, strive to obtain a public self-image or "face" (Goffman 1967). Moreover, American-style FFRs are relatively more expensive to Chinese customers compared with Chinese local fast foods. Therefore, Chinese customers will have higher expectations when dining in American-style FFRs. Also, perceived value will be an important factor to explain the variance of customer satisfaction. In service industries, a good relationship between service providers and customers in collectivist culture that is embedded on trust and a favorable network of personal interactions, is considered a prerequisite for a successful business relationship (for example, Park and Luo 
2001; Laroche et al. 2004, Qin, Prybutok, and Peak 2009). Thus, Chinese customers are more likely to return to the same FFR if they have a satisfactory experience and will be more willing to recommend the FFR to other people. In addition, the behavior of customers can be predicted accurately if the cultural aspects that help to improve customer satisfaction and retention are taken into account. However, few studies have been specifically conducted to test and verify the moderating role of cultural differences in the relationships among service quality, food quality, perceived value, customer satisfaction, and behavioral intentions. Based on the previous discussion, the next thrust of this investigation is to examine the moderating effect of national culture (displayed in Figure 2) on the links in the aforementioned research model. The moderating effect of national culture is shown in Figure 2 in addition to the four hypotheses:

- H5: The relationship between service quality and customer satisfaction is stronger for customers in the United States than for those in China.

- H6: The relationship between perceived value and customer satisfaction is stronger for customers in China than for those in the United States.

- H7: The relationship between food quality and customer satisfaction is stronger for customers in the United States than for those in China.

- H8: The relationship between customer satisfaction and customer behavioral intentions is stronger for customers in China than for those in the United States.

\section{RESEARCH METHOD}

Sampling and Data Collection

In order to investigate behavior intentions for FFRs, following Qin, Prybutok, and Zhao (2010), college students were selected as the convenience sample, because college students are accessible; they dine at FFRs frequently and possess an intuitive understanding of service quality. Moreover, many FFRs choose to target college students as their major customers and own franchises near campuses, especially in China. College students are assumed to represent the upper and middle classes of customers from their respective cultures, which are the markets targeted by most corporations in China (Ueltschy et al. 2004; Laroche et al. 2004). 
Figure 2 Moderating effect of national culture.

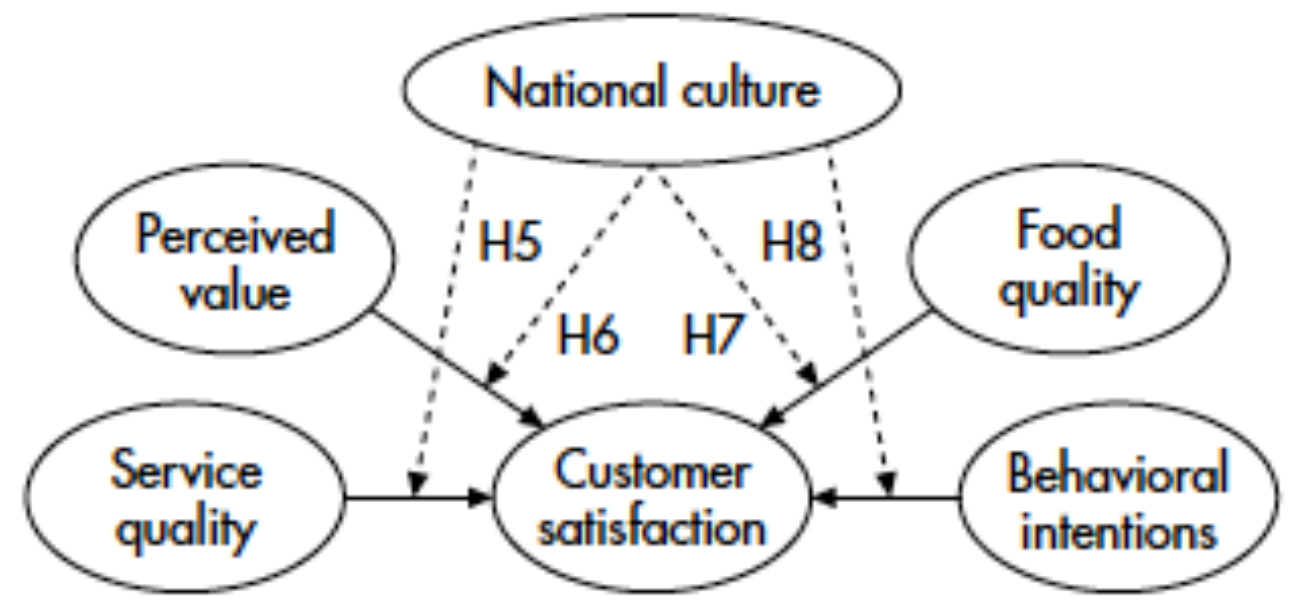

\begin{tabular}{|l|l|l|l|l|}
\hline Table 2 & Demographic information of subjects. \\
\hline \multirow{4}{*}{ Age } & Categories & $\begin{array}{l}\text { Combined } \\
\text { sample }\end{array}$ & $\begin{array}{l}\text { China } \\
\text { sample }\end{array}$ & $\begin{array}{l}\text { America } \\
\text { sample }\end{array}$ \\
\hline & $18-20$ & $27 \%$ & $19 \%$ & $24 \%$ \\
\cline { 2 - 5 } & $21-25$ & $56 \%$ & $73 \%$ & $62 \%$ \\
\cline { 2 - 5 } & $26-30$ & $11 \%$ & $5 \%$ & $8 \%$ \\
\cline { 2 - 5 } & Above 30 & $7 \%$ & $4 \%$ & $6 \%$ \\
\hline \multirow{4}{*}{ Dining } & $1-5$ fimes & $41 \%$ & $92 \%$ & $60 \%$ \\
\cline { 2 - 5 } & $6-10$ times & $32 \%$ & $5 \%$ & $22 \%$ \\
\cline { 2 - 5 } & $\begin{array}{l}\text { Above } 10 \\
\text { fimes }\end{array}$ & $27 \%$ & $3 \%$ & $18 \%$ \\
\hline \multirow{3}{*}{ Gender } & Male & $46 \%$ & $46 \%$ & $46 \%$ \\
\cline { 2 - 5 } & Female & $54 \%$ & $54 \%$ & $54 \%$ \\
\hline
\end{tabular}


Though all of the measuring items were derived from previous literature, the authors realized that a pilot test was necessary to adapt these items to the study context in order to ensure validity of the content. First, several faculty members specializing in the area of service quality management were asked to review the research constructs and the survey instrument. Next, a pilot test was conducted with 20 doctoral students from different academic concentrations to review the questionnaire. Based on their feedback, a few adjustments were made to the wording of the items.

Generally, four approaches, including translation, adaptation, decontextualization, and contextualization, are applied to develop the measures for empirical research in China (Farh, Cannella, and Li 2006). This study uses the translation approach, creating a direct translation of the survey that the authors developed for the U.S. customers in Chinese by a bilingual scholar who is proficient in both English and Chinese. A backtranslation version (Chinese to English) was also created by another bilingual scholar to ensure that questions in the Chinese version were similar to those in the English version and could measure the same variables accurately.

The authors distributed the survey and received 282 usable responses in the United States and 171 usable responses in China, for a total of 453 responses. The respondents included both undergraduate and graduate students representing all of the business majors in the colleges. To ensure that the respondents had enough interactions with FFRs, the dining frequency at FFRs in a one-month period was asked in the survey. Respondents who had dined at FFRs at least once within the last month were included in the sample. The demographic characteristics of the United States and Chinese samples were comparable in this study. Detailed sample statistics are provided in Table 2 for the combined sample and individual samples of Chinese and the U.S. respondents.

\section{Measures}

Constructs and item measurements were borrowed from the literature and modified for this study. To be more specific, the measurement of the five normal dimensions in SERVPERF, including tangibles, reliability, assurance, responsiveness, and empathy, were adapted from Cronin and Taylor (1992), Kara, Kayak, and Kucukemiroglu (1995), and Johns and Howard (1998). Service recoverability in SERVPERF was measured using scales adapted from Olorunniwo et al. (2006). Food quality was measured using scales adapted from Johns and Howard (1998) and Kivela, Inbakaran, and Reece (1999). Perceived value was measured using scales adapted from Kara, Hsu, and Udo (1995) and Kim and Kim (2004). Customer satisfaction was measured using scales adapted from Olorunniwo et al. (2006). Customer behavioral intentions were measured using scales adapted from Boulding et al. (1993) and Keillor, Hult, and Kandemir (2004). The questionnaire items were measured using a seven-point Likert scale (scale ranges from 1 = strongly disagree to 7 = strongly agree). The measurements of service quality, food quality, perceived value, customer satisfaction, and behavioral intentions are listed in 
Appendix 1.

\section{Scale Validation of the Measurement Model}

In this study, the investigation of the hypotheses was conducted using the Partial Least Squares Path Modeling (PLS-PM), a component-based SEM technique. As the covariance-based structure analysis (for example, using LISREL), the PLS is an advanced statistical method that can examine the measurement model together with the structural path (Wold 1982). However, unlike the covariance structure analysis, which requires "multinormality and interval scaling, or sample size required by maximum likelihood estimation" (Fornell and Bookstein 1982, 440), PLS has lower requirements in the minimal sample size, measurement scales, and distribution assumptions (Wold 1982; Chin 1998). Furthermore, PLS can easily work with single-item scales, since the authors needed to test the effect of moderator variables on customer behavioral intentions in this research. PLS-PM is a variance-based SEM methodology that was expanded into marketing and social science research. The distinctive methodological features of PLS-PM make it a possible alternative to the more popular covariancebased SEM approaches, such as LISREL (Henseler, Ringle, and Sinkovics 2009; Hair et al. 2012). Sarstedt, Henseler, and Ringle (2011) also suggest that PLS-SEM is an important empirical research method in international marketing, especially when comparing different groups. Therefore, PLS-PM, rather than covariance-based SEM procedures like LISREL, was chosen to validate this research model and to examine the research hypotheses.

The PLS-Graph version 3.0 was used in scale validation of the measurement model and the hypothesized structural model. To measure the consistency, reliability, and construct validity of the measurement model with all of the latent constructs (including the first-order constructs), CFA in the PLS was conducted following the procedure proposed by Gefen and Straub (2005) and Agarwal and Karahanna (2000). The CFA factor analysis results are shown in Table 3. As shown in the table, except for six items (T3, T5, Empa1, Empa2, Empa6, and Rec4), all 38 items obtained high loading $(>0.70)$ on their respective constructs. Furthermore, they all have higher loadings on their own construct than on the other constructs.

The reliability of the latent constructs was assessed using composite reliability (CR) values. A CR value of 0.7 or higher suggests good reliability (Churchill 1979; Hair et al. 1998). As indicated in Table 3, all of the CR values for the latent factors in this model are between 0.929 and 0.957 , so one can conclude that the reliability of this model is supported. To examine the construct validity, the authors needed to measure two elements: convergent validity and discriminant validity (Straub, Boudreau, and Gefen 2004).

Convergent validity is assessed to measure how strongly each indicator correlates with the latent construct that it is theoretically related to (Gefen and Straub 2005). To estimate convergent validity, factor loading of all items should exceed 0.70 with significant T values, (> 1.96) and the average variance extracted (AVE) values need 
to exceed 0.50 (Fornell and Larcker 1981). Based on the output in Table 4, almost all of the factor loadings are higher than 0.70 . The AVE values are between 0.51 and 0.85 , except for tangibles (0.47), which suggests adequate convergent validity (Fornell and Larcker 1981; Hair et al. 1998).

The discriminant validity is estimated to measure the weakness of each indicator, which correlates with the other latent constructs except for the one it is associated with (Gefen and Straub 2005). To assess the discriminant validity, the authors compare the square root of the AVE values (the average variance shared between the construct and its indicators) with the inter-construct correlation (variance shared between the construct and other constructs) to examine whether the latent construct can explain its indicators better than it explains other constructs. Good discriminant validity requires that the square root of the AVE values be much larger than correlation among any pair of latent constructs (Chin 1998). In Table 4, all of the on-diagonal values (square root of the AVE values) are higher than the bottom off-diagonal values (interconstruct correlations). The results of the comparison suggest adequate discriminant validity for all of the constructs.

\section{RESULTS}

In the measurement model, service quality consists of six dimensions-tangibles, reliability, assurance, responsiveness, empathy, and service recoverability. However, the PLS-Graph version 3.0 does not allow the direct demonstration of first-order and second-order latent constructs in the same model (Yi and Davis 2003). Therefore, the authors employed the procedure proposed by Agarwal and Karahanna (2000) and Yi and Davis (2003) to solve this problem. First, the latent variable scores in a submodel with all of the first-order constructs were calculated using CFA (Gefen and Straub 2005). Afterward, the calculated first-order factor scores were used as manifest indicators of the second-order constructs in the full structural model (Agarwal and Karahanna 2000; Yi and Davis 2003). The factor loadings on the corresponding latent constructs with the second-order model are shown in Table 5.

\section{Full Model With Combined Samples}

The full model with a combined sample of both China and the United States was used to test robust relationships among the constructs and the importance of quality across diverse cultures, because the full sample includes the variations of customer perceptions that are unique to each culture, which leads to a more accurate measurement of SERVPERF and of customer behavioral intentions (Lee 2007). The path coefficient and explained variance (R2) of the endogenous variables are shown in Figure 3. T-values generated with Bootstrap were used to evaluate the significance of the path coefficients in this research. To that end, H1 through $\mathrm{H} 4$ are all supported based on the path coefficient in the output. $\mathrm{H} 1$ and $\mathrm{H} 2$, predicting the positive influence of customer perceived performance of service quality and perceived value on customer satisfaction, were also significantly 
Table 3 CFA of first-order measurement model.

\begin{tabular}{|c|c|c|c|c|c|c|c|c|c|c|}
\hline & $\mathrm{T}$ & Reli & Res & A & Empa & $\operatorname{Rec}$ & CS & PV & $\mathbf{F Q}$ & BI \\
\hline $\mathrm{Tl}$ & 0.71 & 0.57 & 0.53 & 0.54 & 0.46 & 0.49 & 0.46 & 0.27 & 0.48 & 0.44 \\
\hline T2 & 0.70 & 0.58 & 0.56 & 0.59 & 0.41 & 0.51 & 0.44 & 0.20 & 0.47 & 0.44 \\
\hline т3 & 0.63 & 0.32 & 0.40 & 0.34 & 0.15 & 0.36 & 0.29 & 0.20 & 0.31 & 0.29 \\
\hline T4 & 0.69 & 0.41 & 0.36 & 0.28 & 0.38 & 0.29 & 0.34 & 0.44 & 0.38 & 0.40 \\
\hline T5 & 0.60 & 0.34 & 0.26 & 0.23 & 0.36 & 0.22 & 0.29 & 0.46 & 0.34 & 0.37 \\
\hline Relil & 0.55 & 0.83 & 0.66 & 0.60 & 0.51 & 0.59 & 0.52 & 0.37 & 0.56 & 0.51 \\
\hline Reli2 & 0.55 & 0.81 & 0.62 & 0.65 & 0.47 & 0.60 & 0.48 & 0.35 & 0.52 & 0.48 \\
\hline Reli3 & 0.57 & 0.84 & 0.60 & 0.63 & 0.48 & 0.58 & 0.58 & 0.39 & 0.56 & 0.57 \\
\hline Reli4 & 0.57 & 0.86 & 0.65 & 0.61 & 0.50 & 0.54 & 0.54 & 0.40 & 0.55 & 0.53 \\
\hline Reli5 & 0.53 & 0.79 & 0.59 & 0.59 & 0.53 & 0.46 & 0.51 & 0.39 & 0.58 & 0.56 \\
\hline Resl & 0.48 & 0.53 & 0.77 & 0.56 & 0.33 & 0.49 & 0.45 & 0.33 & 0.46 & 0.42 \\
\hline Res2 & 0.56 & 0.69 & 0.90 & 0.70 & 0.51 & 0.64 & 0.57 & 0.41 & 0.62 & 0.57 \\
\hline Res3 & 0.54 & 0.65 & 0.86 & 0.63 & 0.51 & 0.56 & 0.54 & 0.45 & 0.62 & 0.56 \\
\hline Res4 & 0.56 & 0.68 & 0.86 & 0.71 & 0.44 & 0.66 & 0.60 & 0.39 & 0.60 & 0.64 \\
\hline $\mathrm{Al}$ & 0.48 & 0.61 & 0.66 & 0.87 & 0.37 & 0.63 & 0.57 & 0.29 & 0.52 & 0.54 \\
\hline A2 & 0.50 & 0.67 & 0.62 & 0.87 & 0.51 & 0.55 & 0.59 & 0.43 & 0.60 & 0.59 \\
\hline $\mathrm{A} 3$ & 0.52 & 0.66 & 0.72 & 0.89 & 0.43 & 0.67 & 0.59 & 0.40 & 0.55 & 0.60 \\
\hline $\mathrm{A} 4$ & 0.53 & 0.62 & 0.64 & 0.82 & 0.47 & 0.59 & 0.54 & 0.43 & 0.54 & 0.59 \\
\hline Empal & 0.22 & 0.28 & 0.18 & 0.22 & 0.63 & 0.13 & 0.18 & 0.20 & 0.18 & 0.19 \\
\hline Empa2 & 0.11 & 0.12 & 0.10 & 0.13 & 0.40 & 0.21 & 0.02 & 0.06 & 0.00 & 0.00 \\
\hline Empa3 & 0.51 & 0.51 & 0.50 & 0.48 & 0.79 & 0.46 & 0.48 & 0.40 & 0.50 & 0.49 \\
\hline Empa4 & 0.45 & 0.55 & 0.50 & 0.46 & 0.82 & 0.41 & 0.49 & 0.46 & 0.52 & 0.51 \\
\hline Empa5 & 0.47 & 0.55 & 0.48 & 0.45 & 0.82 & 0.44 & 0.52 & 0.50 & 0.55 & 0.54 \\
\hline Empa6 & 0.61 & 0.72 & 0.70 & 0.61 & 0.63 & 0.59 & 0.60 & 0.49 & 0.65 & 0.67 \\
\hline Recl & 0.53 & 0.63 & 0.64 & 0.67 & 0.50 & 0.89 & 0.56 & 0.41 & 0.57 & 0.60 \\
\hline Rec2 & 0.51 & 0.60 & 0.62 & 0.64 & 0.46 & 0.92 & 0.55 & 0.40 & 0.53 & 0.56 \\
\hline Rec3 & 0.53 & 0.63 & 0.66 & 0.66 & 0.44 & 0.91 & 0.55 & 0.42 & 0.57 & 0.62 \\
\hline Rec4 & 0.27 & 0.36 & 0.37 & 0.37 & 0.19 & 0.61 & 0.30 & 0.23 & 0.30 & 0.31 \\
\hline $\mathrm{CS} 1$ & 0.52 & 0.60 & 0.56 & 0.61 & 0.49 & 0.54 & 0.91 & 0.48 & 0.70 & 0.70 \\
\hline $\mathrm{CS} 2$ & 0.49 & 0.59 & 0.57 & 0.62 & 0.49 & 0.54 & 0.95 & 0.47 & 0.69 & 0.73 \\
\hline CS3 & 0.48 & 0.55 & 0.57 & 0.58 & 0.46 & 0.52 & 0.93 & 0.50 & 0.64 & 0.71 \\
\hline $\mathrm{CS} 4$ & 0.52 & 0.61 & 0.64 & 0.64 & 0.48 & 0.59 & 0.90 & 0.47 & 0.66 & 0.73 \\
\hline
\end{tabular}




\begin{tabular}{|c|c|c|c|}
\hline $\begin{array}{l}\text { Construct } \\
\text { measurement }\end{array}$ & Loading & $\begin{array}{l}\text { Standard } \\
\text { error }\end{array}$ & T-Statistic \\
\hline \multicolumn{4}{|l|}{ Service quality } \\
\hline Reliability & 0.89 & 0.01 & 77.18 \\
\hline Assurance & 0.88 & 0.01 & 71.38 \\
\hline Responsiveness & 0.89 & 0.01 & 77.34 \\
\hline Tangibles & 0.80 & 0.02 & 37.93 \\
\hline Empathy & 0.77 & 0.03 & 26.65 \\
\hline Recoverability & 0.83 & 0.02 & 44.90 \\
\hline \multicolumn{4}{|l|}{ Food quality } \\
\hline $\mathrm{Fl}$ & 0.83 & 0.02 & 41.94 \\
\hline $\mathrm{F} 2$ & 0.90 & 0.01 & 80.95 \\
\hline F3 & 0.86 & 0.02 & 39.56 \\
\hline $\mathrm{F}_{4}$ & 0.84 & 0.02 & 53.08 \\
\hline F5 & 0.84 & 0.02 & 41.04 \\
\hline F6 & 0.69 & 0.04 & 17.59 \\
\hline \multicolumn{4}{|l|}{ Perceived value } \\
\hline PV1 & 0.93 & 0.01 & 104.34 \\
\hline PV2 & 0.90 & 0.02 & 51.84 \\
\hline PV3 & 0.88 & 0.01 & 70.76 \\
\hline \multicolumn{4}{|c|}{ Customer satisfaction } \\
\hline $\mathrm{CS} 1$ & 0.91 & 0.01 & 87.05 \\
\hline $\operatorname{CS} 2$ & 0.94 & 0.01 & 155.53 \\
\hline CS3 & 0.92 & 0.01 & 86.73 \\
\hline $\mathrm{CS} 4$ & 0.90 & 0.01 & 78.11 \\
\hline \multicolumn{4}{|c|}{ Behavior intention } \\
\hline BII & 0.92 & 0.01 & 126.33 \\
\hline BI2 & 0.90 & 0.01 & 76.38 \\
\hline B13 & 0.93 & 0.01 & 114.60 \\
\hline
\end{tabular}

$(\gamma=0.37, \mathrm{p}<0.001 ; \gamma=0.11, \mathrm{p}<$ $0.01)$. Food quality has a direct and positive influence on customer satisfaction $(\gamma=0.40, \mathrm{p}<0.001)$, providing significant statistical support for H3. Moreover, customer satisfaction significantly and positively affects customer behavioral intentions $(\beta=0.377, p$ $<0.001$ ), supporting $\mathrm{H} 4$.

The effect of moderator variables on customer behavioral intentions was also tested. Cultural differences (coefficient $=0.083, \mathrm{p}<$ 0.01 ) have a significant influence on behavioral intentions, suggesting that there could be a moderating effect of cultural differences in the relationships among service quality, food quality, perceived value, customer satisfaction, and behavioral intentions. However, age (coefficient $=0.008, \mathrm{p}>0.1$ ) and gender (coefficient $=0.043, p>0.1$ ) do not have significant effects on behavioral intentions. The percentages of male and female subjects in this study are very close, and one can conclude that customer behavioral intentions in FFRs have no differences based on gender. It is important to acknowledge that the limitation of a student sample is that most of the subjects are in the age range of 18 and 25 years old. This could explain the lack of a significant influence of age on customer behavioral intentions in FFRs. 
Figure 3 Structural model with moderator variables for full sample $(n=453)$.

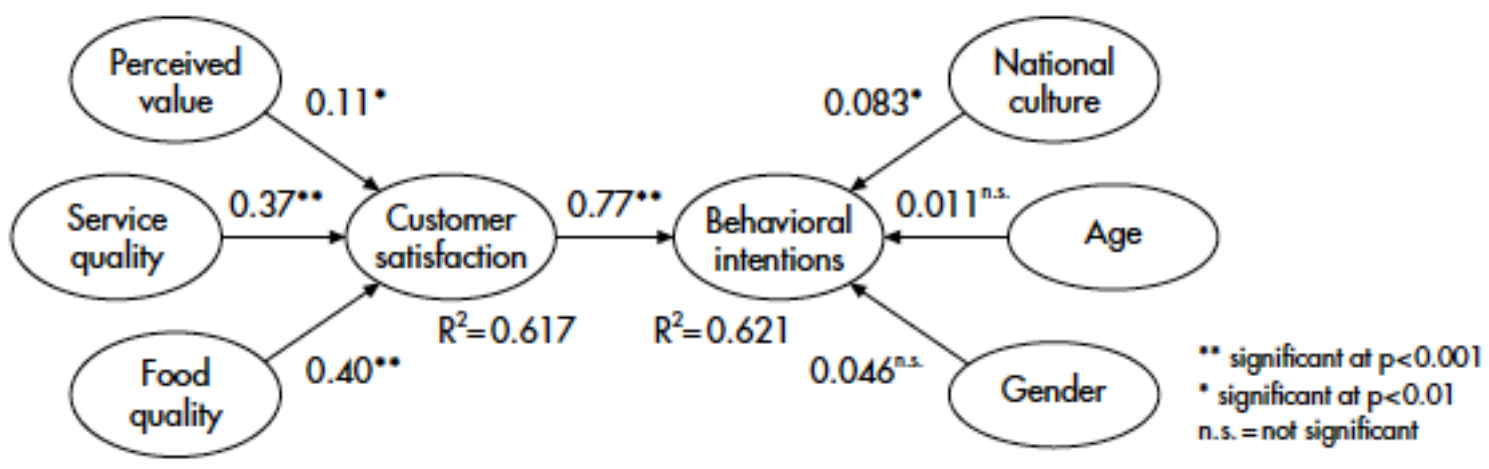

\section{Table 6 Moderating effect analysis (path coefficient comparison).}

\begin{tabular}{|l|c|c|c|c|c|c|c|c|}
\hline Path & $\begin{array}{c}\text { Combined } \\
\text { sample }\end{array}$ & $\begin{array}{c}\text { The U.S. } \\
\text { sample }\left(\mathbf{X}_{1}\right)\end{array}$ & $\begin{array}{c}\text { China } \\
\text { sample }\left(\mathrm{X}_{2}\right)\end{array}$ & $\begin{array}{c}\text { Coefficient } \\
\text { difference }\end{array}$ & $\mathbf{S E}_{1}$ & $\mathbf{S E}_{2}$ & $\mathbf{S}_{\mathbf{x} 1 \times 2}$ & $\boldsymbol{t}$ value \\
\hline $\mathrm{SQ} \rightarrow \mathrm{CS}$ & 0.356 & 0.39 & 0.371 & 0.019 & 0.043 & 0.094 & 0.067 & 2.92 \\
\hline $\mathrm{PV} \rightarrow \mathrm{CS}$ & 0.106 & 0.022 & 0.262 & -0.24 & 0.044 & 0.082 & 0.061 & -40.67 \\
\hline $\mathrm{FQ} \rightarrow \mathrm{CS}$ & 0.409 & 0.463 & 0.208 & 0.255 & 0.059 & 0.040 & 0.052 & 50.31 \\
\hline $\mathrm{CS} \rightarrow \mathrm{BI}$ & 0.776 & 0.73 & 0.925 & -0.195 & 0.059 & 0.034 & 0.051 & -39.42 \\
\hline
\end{tabular}

\section{Moderating Effect of Culture Groups: China vs. the United States}

To test the moderating effect of cultural differences between China and the United States on customer intentions to return, the authors tested the structural model again with separate samples (the Chinese sample and the U.S. sample). After that, the path coefficients of the two separate structural models were collected and compared in Table 6. The significance of the path coefficient difference between two separate models was tested based on the approach proposed by Keil et al. (2000) and Li, Browne, and Wetherbe (2006). This approach is shown in Appendix 2. Based on the results of t tests on the path coefficient differences, all of the path coefficients have significant differences that suggest significant moderating effects on relationships between the latent constructs. As shown in Table 6, the relationship between service quality and customer satisfaction is significantly stronger in the U.S. sample $(\gamma=0.39)$ than in the Chinese sample $(\gamma=0.37)$, supporting H5. The relationship between perceived value and customer satisfaction is not significant $(\gamma$ $=0.022, p>0.10)$ for the U.S. sample, but it is significant $(\gamma=0.262, p<0.01)$ in the Chinese sample. This suggests that the price of fast food will affect Chinese customers' satisfaction with the FFR, but the price is not an important factor affecting American customers' satisfaction. Therefore, H6 is also supported. H7 is supported because the relationship between food quality and customer satisfaction in the United States $(\gamma=0.463)$ is stronger than those for customers in China $(\gamma=$ 0.208). Finally, H8, which stipulated that the relationship between customer 
satisfaction and customer behavioral intentions is stronger for customers in China ( $\beta=0.925)$ than those in the United States $(\beta=0.73)$, is significantly supported.

\section{CONCLUSION AND IMPLICATIONS}

In summary, the authors tested the robust relationships among service quality, food quality, perceived value, customer satisfaction, and behavioral intentions across diverse cultures using a single combined dataset. They also tested the direct influences of moderator variables (such as age group, gender, and national culture) on behavioral intentions. Based on their literature review and the data analysis results, customers with different cultures do have different behavioral intentions. Most importantly, the authors adopted the procedure put forward by Agarwal and Karahanna (2000) and Yi and Davis (2003) to test the moderating effect of culture because it was appropriate for conducting these tests.

The results of this research provide valuable and rare insights into the influence of national culture between individualistic and collectivistic cultures on customers' perceptions of quality, value, satisfaction, and behavioral intentions in the fast-food service industry. A comparison of cultural differences between American and Chinese customers within the context of the fast-food industry can be used as a good example of comparing individualistic cultures and collectivistic cultures in service industries in global marketplaces. First, this paper investigated the relationships among service quality, food quality, perceived value, and customer satisfaction and how they influence customer behavioral intentions in FFRs directly and indirectly across cultures. The relationships among these constructs were tested using combined sample data from the United States and China. Furthermore, this research examines how moderator variables, such as age, gender, and a different culture (individualistic and collectivistic), are related to customers' behavioral intentions. Moreover, this study contributes to cross-culture research by providing a research methodology that can be used to investigate the moderating effects of national culture on the relationships in the theoretical framework.

Sample data were obtained using a questionnaire-based survey from both the United States and China to validate the research model and hypotheses. The modified SERVPERF scale was applied to the measurement instrument and can provide more accurate measurement of service quality by using the cross-cultural data from the United States and China. Results indicate that all of the hypotheses related to the relationships among SERVPERF, food quality, perceived value, customer satisfaction, and behavioral intentions are supported using the full sample from both the United States and China. The hypotheses related to the cultural moderating effects were also supported, and one can conclude that cultural differences influence the relationships in the model.

With regard to managerial implications, when American customers dine at FFRs, they are less sensitive to the perceived value of the fast foods because of the small price range among most of the FFRs in the United States. They have lower 
expectations of the price value of the fast foods, and therefore their perceived value will not contribute much to customer satisfaction in America. However, service quality and food quality becomes more important to improve American customers' satisfaction and intentions to revisit the restaurant. Therefore, it is more important for FFR managers in the United States to understand how customers perceive the service and food quality and what strategies they can use to improve their quality performance. Poor service quality will lead to lower customer satisfaction and decrease the number of paying customers directly. However, superior service and food quality can lead to customer satisfaction and loyalty, which is essential to the growth of sales and profit for FFRs.

Chinese customers are more sensitive to the perceived value of fast food, probably because Chinese local fast-food restaurants have much lower prices than Western fast-food restaurants (Qin, Prybutok, and Zhao 2009). Moreover, with collectivist culture, Chinese customers care more about a public self-image or "face." Therefore, a good relationship between service providers and Chinese customers is more important for them to build a favorable network of personal interactions, which are considered prerequisites of a successful business relationship in China. Thus, fastfood managers need to consider the effect of perceived value and service/food quality comprehensively to provide Chinese customers a more satisfactory experience, which will help maintain a strong relationship with the customers.

The authors believe that this research contributes to the existing service quality research by providing a proper research methodology to examine the moderating effect of cultural differences in different relationships. American FFRs expanding their business to China through franchising need to examine whether product and service quality can continue to satisfy new customers who exhibit different cultural expectations. Intense competition in this industry calls for a better understanding of how their services are perceived by customers in different cultural environments. The findings of this study provide guidelines for FFR franchisers in the United States and franchisees in China.

\section{REFERENCES}

Agarwal, R., and E. Karahanna. 2000. Time flies when you're having fun: Cognitive absorption and beliefs about information technology usage. MIS Quarterly 24, no. 4:665-694.

Boulding, W., A. Kalra, R. Staelin, and V. A. Zeithaml. 1993. A dynamic process model of service quality: From expectations to behavioral intentions. Journal of Marketing Research 30, no. 2:7-27.

Brady, M. K., C. J. Robertson, and J. J. Cronin. 2001. Managing behavioral intentions in diverse cultural environments: An investigation of service quality, service value, and satisfaction for American and Ecuadorian fast-food customers. Journal of International Management 7, no. 2:129-149. 
Chan, H., and L. C. Wan. 2008. Consumer responses to service failures: A resource preference model of cultural influences. Journal of International Marketing 16, no. 1:72-97.

Chin, W. W. 1998. Issues and opinion on structural equation modeling. MIS Quarterly 22, no. 1:vii-xvi.

Churchill, G. A. 1979. A paradigm for developing better measures of marketing constructs. Journal of Marketing Research 16, no. 1:555-562.

Cronin, J. J., and S. A. Taylor. 1992. Measuring service quality: A reexamination and extension. Journal of Marketing 56, no. 3:55-68.

Datamonitor 2010. Fast food: Global industry guide. Available at: http://www.reportbuyer.com/leisure_media/dining/fast_food/ fast_food_global_industry_guide.html.

Fan, J. X., and J. J. Xiao. 1998. Customer decision-making styles of young Chinese. Journal of Consumer Affairs 32:275-294.

Farh, J. L., A. A., Cannella, and C. Li. 2006. Approaches to scale development in Chinese management research. Management and Organizational Review 2, no. 3:301-318.

Fornell, C., and D. F. Larcker. 1981. Evaluating structural equations with unobservable variables and measurement error. Journal of Marketing Research 18, no. 1:39-50.

Fornell, C., and F. Bookstein. 1982. Two structural equation models: LISREL and PLS applied to consumer exit-voice theory. Journal of Marketing Research 19:440-452.

Friedman, R., S. C. Chi, and L. A. Liu. 2006. An expectancy model of Chinese-American differences in conflict-avoiding. Journal of International Business Studies 37:76-91.

Furrer, O., B. S. Liu, and D. Sudharshan. 2000. The relationships between culture and service quality perceptions. Journal of Service Research 2, no. 4:355-371.

Gefen, D., and D. Straub. 2005. A practical guide to factorial validity using PLSGRAPH: Tutorial and annotated example. Communications of the Association for Information Systems. 16:91-109.

Gilbert, G. R., C. Veloutsou, M. Goode, and L. Moutinho. 2004. Measuring customer satisfaction in the fast food industry: A crossnational approach. The Journal of Services Marketing 18, no. 5:371-383. 
Gilbert, G. R., and C. Veloutsou. 2006. A cross-industry comparison of customer satisfaction. The Journal of Services Marketing 20, no. 5:298-308.

Goffman, E. 1967. Interaction ritual: Essays on face-to-face interaction. Garden City, NY: Doubleday.

Hair, J. F., R. E. Anderson, R. L. Tatham, and W. Black. 1998. Multivariate data analysis. Upper Saddle River, NJ: Prentice-Hall, Inc.

Hair, J. F., M. Sarstedt, C. M. Ringle, and J. A., Mena. 2012. An assessment of the use of partial least squares structural equation modeling in marketing research. Journal of the Academic Marketing Science no. 40:414-433.

Henseler, J., C. M. Ringle, and R. R. Sinkovics. 2009. The use of partial least squares path modeling in international marketing. Advances in International Marketing no. 20:277-319.

Hofstede, G. 1991. Cultures and organizations: Software of the mind. London: McGraw-Hill.

Jain, S. K., and G. Gupta. 2004. Measuring service quality: SERVQUAL vs. SERVPERF scales. VIKALPA 29, no. 2:25-37.

Johns, N., and A. Howard. 1998. Customer expectations versus perceptions of service performance in the foodservice industry. International Journal of Service Industry Management 9, no. 3:248-256.

Kara, A., E. Kaynak, and O. Kucukemiroglu. 1995. Marketing strategies for fast-food restaurants: A customer view. International Journal of Contemporary Hospitality Management 7, no. 4:16-22.

Keil, M., B. C. Y. Tan, K. K. Wei, T. Saarinen, V. Tuunainen, and A. Wassenaar. 2000. A cross-cultural study on escalation of commitment behavior in software projects. MIS Quarterly 24, no. 2:299-325.

Keillor, B. D., G. T. M. Hult, and D. Kandemir. 2004. A study of service encounter in eight countries. Journal of International Marketing 12, no. 1:9-35.

Kim, W. G., and H. B. Kim. 2004. Measuring customerbased restaurant brand equity. Cornell Hotel and Restaurant Administration Quarterly 45, no. 2:115-131.

Kim, D., L. Wen, and K. Doh. 2010. Does cultural difference affect customer's response in a crowded restaurant environment? A comparison of American versus Chinese customers. Journal of Hospitality \& Tourism Research 34, no. 1:103-123.

Kivela, J., R. Inbakaran, and J. Reece. 1999. Consumer research in the restaurant 
environment, Part 1: A conceptual model of dining satisfaction and return patronage. International Journal of Contemporary Hospitality Management, 11, no. 5:205-222.

Laroche, M., L. C. Ueltschy, S. Abe, M. Cleveland, and P. P. Yannopoulos. 2004. Service quality perceptions and customer satisfaction: Evaluating the role of culture. Journal of International Marketing 12, no. 3:58-85.

Law, A. K. Y., Y. V. Hui, and X. Zhao. 2004. Modeling repurchase frequency and customer satisfaction for fast food outlets. International Journal of Quality \& Reliability Management. 21, no. 5:545-563.

Lee, M., and F. M. Ulgado. 1997. Customer evaluation of fast-food services: A cross-national comparison. The Journal of Services Marketing 11, no. 1:39-52.

Lee, J. 2007. SERVQUAL vs. SERVPERF: Round 2 in a multicultural setting. Journal of Academy of Business and Economics 7, no. 3:77-96.

Li, D., G. J. Browne, and J. C. Wetherbe. 2006. Why do Internet users stick with a specific web site? A relationship perspective. International Journal of Electronic Commerce 10, no. 4:105-141.

Malhotra, N. K., F. M., Ulgado, J. Agarwal, and L. Wu. 2005. Dimensions of service quality in developed and developing economics: Multi-country cross-cultural comparisons. International Marketing Review 22, no. 3:256-78.

Mattila, A. S. 1999. The role of culture in the service evaluation processes. Journal of Service Research 1, no. 3:250-261.

Olorunniwo, F., M. K. Hsu, and G. J. Udo. 2006. Service quality, customer satisfaction, and behavioral intentions in the service factory. Journal of Services Marketing 20, no. 1:59-72.

Parasuraman, A., V. A. Zeithaml, and L. L. Berry. 1985. A conceptual model of service quality and its implications for future research. Journal of Marketing 49, no. 4:41-50.

Parasuraman, A., V. A. Zeithaml, and L. L. Berry 1988. SERVQUAL: A multiple-item scale for measuring consumer perceptions of service quality. Journal of Retailing 64, no. 1:12-40.

Park, S. H., and Y. Luo. 2001. Guanxi and organizational dynamics: Organizational networking in Chinese firms. Strategic Management Journal 22, no. 2:455-477.

Qin, H., and V. R. Prybutok. 2008. Determinants of customerperceived service quality in fast food restaurants (FFRs) and their relationship to customer 
satisfaction and behavioral intentions. Quality Management Journal 15, no. 2:35-50.

Qin, H., and V. R. Prybutok. 2009. Service quality, customer satisfaction, and behavioral intentions in fast-food restaurants. International Journal of Quality and Service Sciences 1, no. 1:78-95.

Qin, H., V. R. Prybutok, and D. A. Peak. 2009. Service quality in the United States' and mainland China's fast-food restaurants. International Journal of Services and Standards 5, no. 4:291-315.

Qin, H., V. R. Prybutok, and Q. Zhao. 2010. Perceived service quality in fast-food restaurants: Empirical evidence from China. International Journal of Quality and Reliability Management 27, no. 4:424-437.

RNCOS E-Services Private Limited. 2008. China fast food analysis. Available at: http://www.researchandmarkets.com/reportinfo.asp?cat_id=0\&report_id=656464 $\& q=$ fast food $\& p=1$.

Ryu, K., H. Han, and S. Jang. 2010. Relationships among hedonic and utilitarian values, satisfaction, and behavioral intentions in the fast-casual restaurant industry. International Journal of Contemporary Hospitality Management 22, no. 3:416-432.

Sarstedt, M., J. Henseler, and C. M., Ringle. 2011. Multi-group analysis in partial least squares (PLS) path modeling: Alternative methods and empirical results. Advances in International Marketing no. 22:195-218.

Straub, D., M. C. Boudreau, and D. Gefen. 2004. Validation guidelines for IS positivist research. Communications of the Association for Information Systems 14:380-426.

Ueltschy, L. C., M. Laroche, R. D. Tamilia, and P. Yannopoulos. 2004. Cross-cultural invariance of measures of satisfaction and service quality. Journal of Business Research 7:901-912.

Witkowski, T. H., and M. F. Wolfinbarger. 2002. Comparative service quality: German and American ratings across service settings. Journal of Business Research 55:875881.

Wold, H. 1982. Soft modeling: The basic design and some extensions. System Under Indirect Observations 2:589-591.

Yi, M. Y., and F. D. Davis. 2003. Developing and validating an observational learning model of computer software training and skill acquisition. Information Systems Research 14, no. 2:146-169.

\section{BIOGRAPHIES}


Chao Wen is an assistant professor in the School of Business at Eastern Illinois University. He received his doctorate in management science from the University of North Texas. Wen obtained his master's in science degree with a concentration in supply chain management and bachelor's degree in computer science from the University of Electronic Science \& Technology of China. Wen has published journal articles in the Journal of Computer Information Systems, Cyberpsychology Behavior and Social Networking, Information \& Management, and International Journal of Services Technology and Management. His research interests include e-commerce, consumer behavior, service operations, statistics education, and supply chain management. He can be reached by email at cwen@eiu.edu.

Hong Qin is an assistant professor at The University of TexasPan American. She received her doctoral degree from The University of North Texas. Her teaching areas include business statistics, multivariate statistics, and management science. Some of her more recent publications can be found in the International Journal of Quality and Service Sciences, International Journal of Services and Standards, and Quality Management Journal. Qin is also a board council member of the Decision Sciences Institute-Southwest Region.

Victor R. Prybutok is a Regents professor of decision sciences in the Information Technology and Decision Sciences Department and associate dean of the Toulouse Graduate School at the University of North Texas. He received his bachelor's degree from Drexel University, a master's degree in bio-mathematics, a master's degree in environmental health in 1980, and a doctorate in environmental analysis and applied statistics. He is a senior member of ASQ and active in the American Statistical Association, Decision Sciences Institute, Institute of Electrical and Electronic Engineers, and Operations Research Society of America. Prybutok is an AS Q certified quality engineer, certified quality auditor, certified manager of quality/organizational excellence, and an accredited professional statistician (PSTAT®) by the American Statistical Association.

Charles Blankson is an associate professor of marketing, and received his doctorate in marketing from Kingston University, London, U.K., and his master's degree in marketing from Staffordshire University, Stoke-on-Trent, U.K. He has a postgraduate certificate in education (PGCE) - a U.K. teachers' qualifying certificate from the University of Greenwich, London, U.K. He holds the professional marketing diploma (Dip. M.) from the Chartered Institute of Marketing, U.K., and is a member of the Chartered Institute of Marketing, the American Marketing Association, and the Academy of Marketing Science. He held managerial positions with Burger King (U.K.) Ltd. and the London Borough of Wandsworth, and graduate trainee positions with Marks \& Spencer Stores Ltd. and Harrods Store Ltd. Blankson has been a visiting scholar in marketing at Kingston University Business School and the University of Ghana Business School. In addition, he supervises masters' theses at Kingston University Business School and doctoral theses at the University of Ghana Business School. He initiated, researched, and successfully set up a memorandum of understanding (MOU) between the University of North Texas and the University of 
Ghana.

\section{Appendix 1}

\section{Scales and Items}

Service Quality

Tangibles

T1. Dining area is clean.

T2. Employees are well dressed and appear neat.

T3. Employees wear disposable plastic gloves and hair net.

T4. Seats are available for dining.

T5. Ample parking is available.

\section{Responsiveness}

Res1. Its employees tell you exactly when services will be performed.

Res2. Its employees are available to respond to your requests promptly.

Res3. You receive prompt service.

Res4. Its employees are always willing to help you.

\section{Empathy}

Empa1. A kid's meal with a toy is available.

Empa2. An indoor children's entertainment center is available.

Empa3. The availability of sauces, utensils, and other essentials is good.

Empa4. It has convenient operating hours.

Empa5. It has convenient locations.

Empa6. Your food order is correct and complete.

Recoverability

Rec1. Its employees quickly apologize when service mistakes are made.

Rec2. It cares about customers' complaints.

Rec3. Its employees have effective skills and ability to deal with customers' complaints.

Rec4. Its employees are empowered to provide compensations for inaccurate service.

Reliability

Reli1. This FFR is prompt in meeting all of its promises.

Reli2. When you have problems, this FFR is sympathetic and reassuring.

Reli3. This FFR is dependable.

Reli4. This FFR provides services at the time it promises.

Reli5. You are charged accurately.

Assurance

A1. You can trust the employees in this FFR. 
A2. You feel safe conducting financial transactions with the employees.

A3. Its employees are consistently friendly and courteous.

A4. Its employees are knowledgeable about your food and beverage questions.

\section{Perceived Value}

PV1. The prices of food at this FFR are competitive.

PV2. The prices of beverage at this FFR are competitive.

PV3. You receive good value for the price at this FFR.

\section{Food Quality}

FQ1. The food at this FFR is fresh.

FQ2. The food at this FFR is tasty.

FQ3. The food at this FFR is served hot.

FQ4. The food at this FFR is well presented.

FQ5. The food at this FFR is well cooked.

FQ6. A variety of food and beverages are available at this FFR.

\section{Customer Satisfaction}

CS1. You are satisfied with your decision to dine at this FFR.

CS2. Your choice to dine at this FFR was a wise one.

CS3. You think you did the right thing when you chose to dine at this FFR.

CS4. You feel that your experience with this FFR has been enjoyable.

\section{Behavior Intentions}

BI1. You will recommend this FFR to others.

BI2. You intend to dine in this FFR in the future.

BI3. If asked, you will say good things about this FFR.

\section{Appendix 2}

\section{Path Coefficient Difference Comparison Method}

The procedure used here to test the significant difference between the U.S. sample and the Chinese sample is from Keil et al. (2000) and Li, Browne, and Wetherbe (2006). The $t$ value is calculated based on equation (1):

$$
t=\frac{x_{1}-x_{2}}{S_{x 1 \times x 2^{2}} * \sqrt{1 / n_{1}+1 / n_{2}}}
$$

Where ni is the sample size for the U.S. and Chinese samples, ( $\mathrm{n} 1=282$ for the U.S. sample; $\mathrm{n} 2$ = 171 for the Chinese sample); 
$\mathrm{Xi}$ is the path coefficient in the structural model for the U.S. sample ( $\mathrm{i}=1)$ and the Chinese sample $(\mathrm{i}=2) . \mathrm{Sx} 1^{*} \mathrm{x} 2$ is the estimator of pooled variance, which one can calculate using equation (2):

$$
S_{x 1 \cdot x 2}=\sqrt{\frac{\left(n_{1}-1\right) * S E_{1}^{2}+\left(n_{2}-1\right) * S E_{2}^{2}}{n_{1}+n_{2}-2}}
$$

Where SEi is the standard error of path in the structural model for the U.S. sample (i $=1$ ) and the Chinese sample $(\mathrm{i}=2)$. 